\title{
A RESPONSABILIDADE INTERNACIONAL DOS ESTADOS PERANTE TRIBUNAIS INTERNACIONAIS
}

THE INTERNATIONAL RESPONSIBILITY OF STATES TOWARD INTERNATIONAL COURTS

\section{Isis De Angellis Sanches Alexandrino ${ }^{1}$}

ISSUE DOI: $10.21207 / 1983.4225 .492$

\section{RESUMO}

O objetivo geral do presente trabalho é a busca do entendimento da responsabilidade internacional do Estado. A responsabilidade internacional do Estado possui uma existência precária, pois faltam poder central vinculante e mecanismos mais eficazes de coação estatal, como mecanismos de execução automática de sentenças internacionais. A sociedade internacional é descentralizada e uma norma de Direito Internacional só pode ser superior às outras porque os Estados a aceitaram, como é o caso da Carta das Nações Unidas, em virtude de seu artigo 103. Há um estudo, o Draft Articles on Responsibility of States for Internationally Wrongful Acts que

${ }^{1}$ Graduada em Direito pela Faculdade de Direito de Franca (2015). Especialista em Direito Tributário na Faculdade de Direito de Ribeirão Preto (2016). 
foi aprovado pela Comissão de Direito Internacional das Nações Unidas, e que é essencial para a aplicação da responsabilidade internacional do Estado. No âmbito civil, a responsabilidade é de natureza compensatória e objetiva, a qual prescinde da prova de culpa, sendo tão somente necessário demonstrar o nexo de causalidade entre o comportamento e o dano. Todas as vezes que não se puder vislumbrar o nexo de causalidade entre o comportamento da Administração e o prejuízo sofrido pelo lesado não se poderá afirmar a existência de responsabilidade objetiva. Essa situação costuma ocorrer quando a vítima age com culpa ou dolo. As lesões aos direitos de estrangeiros praticadas por particulares dentro dos Estados não acarretam a responsabilidade internacional do Estado. Neste caso, a solução seria a de responsabilizar o autor do ato nas esferas civil e criminal. A responsabilidade penal, no Direito Internacional, só possui lugar excepcionalmente, como nos casos de genocídio, dos crimes de guerra e dos crimes contra a humanidade, o que já caracteriza a responsabilidade pessoal do indivíduo (notadamente perante o Tribunal Penal Internacional). A proteção diplomática é aquela em que se opera de Estado para Estado. Ocorre que o indivíduo vítima de violação ajuíza uma queixa, chamada de reclamação ao Estado de sua nacionalidade para que este a proteja internacionalmente. Quando o Estado oferece essa proteção ele endossa a reclamação da vítima e toma como sua a queixa alegada. O direito de proteção diplomática pertence ao Estado e não ao reclamante. Dessa maneira, mesmo que o estrangeiro pretenda ir a um país para fazer negócios e renuncie à proteção diplomática, (doutrina Calvo) são os Estados nacionais de tais estrangeiros que detêm a proteção diplomática e não o reclamante. Por consequência, essas cláusulas não os privam em absoluto da proteção diplomática. Ademais, há a subsidiariedade do sistema protetivo internacional relativamente ao sistema judiciário interno, devendo haver o prévio esgotamento dos recursos internos para que os Tribunais Internacionais atuem. São excludentes de responsabilidade do Estado a legítima defesa; as contramedidas, a força maior; o perigo extremo; o estado de necessidade e a renúncia do indivíduo lesado.

Palavras-chave: responsabilidade internacional do Estado; Tribunais Internacionais.

\section{ABSTRACT}


The goal of this study is to understand how the international responsibility of the States occurs. The international responsibility of the states has a precarious existence, because there is a lack of central binding power and mechanisms more effective to persuade the states, as mechanisms for the automatic execution of international judgments. The international society is decentralized and a rule of international law can only be superior to others because the States have accepted it, and that is the case of the Charter of the United States, and it is due to its article 103. There is a study of the Draft Articles on Responsibility of States for Internationally Wrongful Acts that was authorized by the International Law Comission of the United Nations, as an essential document to enforce the international responsibility of the States in an international order. In the civil sphere, liability is compensatory and objective. In the civil sphere, it is not necessary to evidence the fault of the state, it is only necessary to demonstrate the causal link between the behavior and the damage. Whenever the causal link between the conduct of the administration and the damage suffered by the harmed person could not be demonstrated, the liability of the State will not be discriminated, and there would not have the existence of an strict liability. This situation usually occurs when the victim act with guilt and guile. Damages to the rights of foreigners practiced by individuals inside the States territory do not entail the international responsibility of the State. In this case, the solution would be to hold the perpetrator responsibility in the civil and criminal spheres. Criminal responsibility in the international law only takes place exceptionally, as cases of genocide, war crimes and crimes against humanity, which already characterizes the personal responsibility of the individual (notably before the International Criminal Court). Diplomatic protection operates from state to state. The individual who suffered a violation request a complaint, called reclamation, to the State of its nationality. That occurs for him to become protected internationally. When the State offers this protection it endorses a claim from the victim and receive it as it were their own complaint. The right of diplomatic protection belongs to the State and it do not belong to the claimant. Thus, even if the foreigner intends to go to a country to do business and renounce to a diplomatic protection, (Calvo doctrine) the State of the foreigners is the one who holds diplomatic protection, the claimant can not do it. Consequently, these clauses do not deprive them of diplomatic protection at all. In addition, there is the subsidiarity of some International Tribunals toward the internal judicial system, and the previous exhaustion of domestic remedies must occur before the Interna- 
tional Tribunal ensues it. There are some situations that remove the responsibility of the State, such as, self-defense; countermeasures, force majeure; the extreme danger; the state of necessity; and the resignation of the individual damage.

Key words: international responsibility of the State; International Tribunals

\section{INTRODUÇÃO}

A tradição jurídica da teoria do Direito assinala a necessidade de serem as normas gerais e abstratas emanadas de uma autoridade e providas de sanção para o caso de seu descumprimento. Quanto ao Direito Internacional público, a sanção emanando de uma autoridade conjunta quando os Estados infringem as suas regras é representada pelo instituto da responsabilidade internacional, pois, a responsabilidade deste é corolário lógico quando há o cometimento de um ato ilícito.

A responsabilidade internacional do Estado possui uma existência precária, pois falta poder central vinculante e mecanismos mais eficazes de coação estatal, como mecanismos de execução automática de sentenças internacionais. A finalidade essencial do instituto é, em última análise, reparar e satisfazer, respectivamente, os danos materiais e éticos sofridos por um Estado em decorrência de atos praticados por outro.

Abordou-se um estudo sobre o Draft Articles on Responsibility of States for Internationally Wrongful Acts aprovado pela Comissão de Direito Internacional das Nações Unidas, essencial para a aplicação da responsabilidade internacional do Estado. O draft elaborado pela CDI já tem servido de guia para vários tribunais internacionais.

O direito internacional público surgiu do agrupamento de seres humanos pelas várias regiões do planeta, o que fomentou a criação de blocos de indivíduos com características comuns (sociais, culturais, religiosas, políticas, etc.). A partir do momento que dada comunidade passou a ultrapassar os impedimentos físicos que o planeta lhe impõe (montanhas, florestas, desertos, mares etc.) e a descobrir que existem outras comunidades espalhadas pelos quatro cantos da Terra, surgiu a necessidade de coexistência entre elas. Com características tão diferentes, esses povos acabaram por desprezar as características sociais, econômicas e políticas de cada uma das partes e acabaram por se suportarem assim 
como numa relação contratual, dando lugar a uma relação negocial entre elas.

Por isso, tornou-se necessária a criação de determinadas normas de conduta, a fim de reger a vida em grupo para a regulamentação e harmonizações de interesses mútuos. Em decorrência dessa evolução e na medida em que cresceram os intercâmbios, o Direito passou a reger situações não mais limitadas às fronteiras territoriais e passou a não mais somente regular questões internas. Este passou a disciplinar também atividades que transcendem os limites físicos dos Estados, criando um conjunto de normas capazes de realizar esse mister.

Nessas normas, não há a existência de um poder centralizado de Direito Internacional. Portanto a sociedade internacional é descentralizada. Entretanto, uma norma de Direito Internacional pode ser superior às outras como é o caso da Carta das Nações Unidas, em virtude de seu artigo 103. Se uma norma é superior às outras é porque os Estados a aceitaram.

De acordo com a Carta das Nações Unidas:

Art. 103. No caso de conflito entre as obrigações dos membros das Nações Unidas em virtude da presente Carta e as obrigações resultantes de qualquer outro acordo internacional, prevalecerão as obrigações assumidas em virtude da presente Carta.

A Declaração Universal de 1948, apesar de ser norma de jus cogens internacional não dispõe de meios técnicos para que alguém (que teve seus direitos violados) possa aplicá-la na prática.

Tal não significa, contudo, que não exista no plano do Direito Internacional um sistema de sanções, notadamente no âmbito das Nações Unidas. Porém esse sistema de sanções não é suficiente visto que não existe ainda na órbita internacional (ao contrário do que ocorre no Direito Interno) nenhum órgão com jurisdição geral capaz de obrigar os Estados a decidirem ali suas contendas. A participação dos Estados em tribunais internacionais requer o consentimento expresso destes, sem o qual o tribunal respectivo não poderá exercer jurisdição sobre eles. Um exemplo é a Corte Interamericana de Direitos Humanos, da qual o Brasil participa.

O Direito Internacional Público ou Direito das Gentes normalmente, mas não necessariamente, se destina aos sujeitos (ou pessoas) e 
também acaba por prever as condutas destas. Podem ser sujeitos ativos (como a capacidade de um Estado manter relações com outras potências estrangeiras) e passivos (como quando um indivíduo peticiona a uma corte internacional de direitos humanos vindicando seus direitos violados).

Assim, sob o primeiro ponto de vista, são sujeitos de Direito Internacional Público as pessoas às quais as normas internacionais atribuem direitos e obrigações, e em segundo lugar, a noção de personalidade jurídica no plano internacional entendendo-se como a capacidade de agir internacionalmente. São considerados sujeitos os Estados, as coletividades interestatais, as coletividades não estatais e os indivíduos (ou particulares).

Ocorre que houve uma evolução quanto à responsabilidade desses sujeitos de direitos internacionais perante danos causados a terceiros, principalmente no âmbito dos direitos humanos. A responsabilidade civil é diversa da responsabilidade criminal e administrativa, não obstante possam elas coexistirem. No âmbito civil, a responsabilidade é de natureza compensatória e objetiva, na qual prescinde da prova de culpa, sendo tão somente necessário demonstrar o nexo de causalidade entre o comportamento e o dano. Todas as vezes que não se se puder vislumbrar o nexo de causalidade entre o comportamento da Administração e o prejuízo sofrido pelo lesado não se poderá afirmar a existência de responsabilidade objetiva. Essa situação costuma ocorrer quando a vítima age com culpa ou dolo.

\section{CONSIDERAÇÕES INICIAIS}

As normas internacionais são gerais e abstratas e por serem normas jurídicas são emanadas por uma autoridade conjunta, composta por autores internacionais juridicamente coordenados e em pé de igualdade e possuem variados meios de resposta ao descumprimento as suas regras, assim providas de sanção em caso de descumprimento.

Consoante Francisco Rezek, em seu livro Direito internacional público, o conceito de responsabilidade internacional seria:

O Estado responsável pela prática de um ato ilícito segundo o direito internacional deve ao Estado a que 
tal ato tenha causado um dano uma reparação adequada. É essa, em linhas simples, a ideia da responsabilidade internacional. Cuida-se de uma relação entre sujeitos de direito das gentes: tanto vale dizer que, apesar de deduzido em linguagem tradicional, com mera referência a Estados, o conceito se aplica igualmente às organizações internacionais. Uma organização pode, com efeito, incidir em conduta internacionalmente ilícita, arcando assim com sua responsabilidade perante aquela outra pessoa jurídica de direito das gentes que tenha sofrido o dano; e pode, por igual, figurar a vítima do ilícito, tendo neste caso direito a uma reparação².

Assinala Antônio Cassesse que:

Como se percebe, o conceito de responsabilidade no contexto internacional é muito mais coletivo que individual. Quando um agente ou funcionário do Estado erra e comete violação de direito de outrem, ou quando um tribunal interno deixa de aplicar um tratado vigente, negando eventual direito a um estrangeiro protegido por esse tratado, é o Estado para o qual o agente trabalha que, em princípio, responde pelo dano na órbita internacional (ainda que os indivíduos que o compõem nada tenham a ver com o ilícito cometido). A responsabilidade individual (agora mais nítida com a criação do Tribunal Penal Internacional) é, por sua vez, subsidiária das jurisdições estatais e tem um relevo por enquanto menor no plano externo, não obstante a condenação de indivíduos em tribunais penais internacionais encontrar-se cada vez mais em voga ${ }^{3}$.

${ }^{2}$ RESEK, Francisco. Direito internacional público.13. ed. Cidade: São Paulo, Saraiva, 2012. p. 315.

${ }^{3}$ CASSESE apud MAZZUOLI, Valerio de Oliveira. Diritto Internazionale. cit., pp. 20-21. 
$\mathrm{O}$ instituto da responsabilidade internacional tem uma existência precária, pois a sociedade internacional é descentralizada visto que falta poder central vinculante e mecanismos mais eficazes de coação internacional ${ }^{4}$.

James Crawford citado por Valério de Oliveira Mazzuoli, assevera que a Comissão de Direito Internacional das Nações Unidas aprovou, em sua $48^{\circ}$ Sessão, o texto do primeiro projeto (draft) de convenção internacional sobre responsabilidade do Estado por atos internacionalmente ilícitos, (Draft Articles on Responsibility of States for Internationally Wrongful Acts) desenvolvido com base nos trabalhos de sistematização do Prof. Roberto Ago. Posteriormente, atendendo às críticas de alguns países, o projeto inicial (a partir de 1997) foi revisto pela mesma Comissão, agora sob a relatoria do Prof. James Crawford, e finalmente aprovado em 9 de agosto de 2001 , na sua $53^{\circ}$ Sessão. Após sua aprovação, o projeto foi encaminhado à Assembleia-Geral da ONU para que esta verifique, mas até o presente momento não ocorreu a possibilidade de adoção do seu texto, abrindo-se a oportunidade para as assinaturas e respectivas ratificações dos Estados. Frise-se que, na ONU, o draft poderá sofrer alterações por sugestão dos Estados, quando então um texto possivelmente diverso do originalmente apresentado poderá ser adotado pela $\mathrm{CDI}^{5}$.

Apesar de não passar de um projeto de convenção sobre responsabilidade dos Estados, sequer ainda adotado e em vigor, o certo, contudo, é que o draft elaborado pela CDI já tem servido de guia para vários tribunais internacionais, dentre eles a própria CIJ (influenciando também a doutrina etc.). Daí o motivo em se estudar o projeto em sua fase atual ${ }^{6}$.

Quanto ao conceito de responsabilidade internacional, assim como os atos ilícitos praticados pelos cidadãos merecem uma devida reprimenda; a prática de um ato ilícito internacional, entendido este como todo ato violador de uma norma de DIP, por parte de um Estado em relação aos direitos de outro, gera igualmente a responsabilização do causa-

${ }^{4}$ MAZZUOLI, Valerio de Oliveira. Curso de direito internacional público. 7. Ed. Rev. dos Tribunais, 2013.

${ }^{5}$ Cf. CRAWFORD, James. The International Law Commission's articles on State responsibility: introduction, text and commentaries.Cambridge: Cambridge University Press, 2002. p. 391.

${ }^{6}$ MAZZUOLI, Valerio de Oliveira. Curso de direito internacional público. 7. ed. Rev. dos Tribunais, 2013. p. 588. 
dor do dano, em relação àquele Estado contra o qual o ato ilícito foi cometido. Portanto, é princípio próprio do direito das gentes que "todo fato internacionalmente ilícito de um Estado gera a sua responsabilidade internacional $\left(\operatorname{art} .1^{\circ}\right)^{7}$ "

Sob a perspectiva de Hildebrando Accioly,

A responsabilidade internacional do Estado é o instituto jurídico que visa responsabilizar determinado Estado pela prática de um ato atentatório (ilícito) ao Direito Internacional perpetrado contra os direitos ou a dignidade de outro Estado, prevendo certa reparação a este último pelos prejuízos e gravames que injustamente sofreu ${ }^{8}$.

De acordo com José Francisco Resek, citado por Mazzuoli:

$\mathrm{O}$ caso célere que deflagrou a moderna teoria da responsabilidade internacional do Estado ocorreu em 17 de setembro 1948, quando o mediador da ONU na Palestina, o conde sueco Folke Bernadotte, foi assassinado em Jerusalém. Junto com ele morreu o coronel André Sérot, que liderava os observadores franceses. Vários outros agentes internacionais sofreram danos pessoais, em relação aos quais reclamaram indenização. A ONU então, por meio de Resolução de 3 de dezembro de 1948, solicitou um parecer consultivo à CIJ, a qual, em 11 de abril de 1949, manifestou - se no sentido de poder a organização internacional apresentar ao governo de jure ou de facto responsável pelo ilícito - que não se confunde com o mal diretamente sofrido pelas vítimas e seus sucessores - uma reclamação, a fim de poder reparar - se do dano sofrido. Entendeu a Corte que a ONU, como sujeito de direito das gentes que é detentora de personalidade jurídica distinta da dos

${ }^{7}$ MAZZUOLI, Valerio de Oliveira. Curso de direito internacional público. 7. ed. Rev. dos Tribunais, 2013. p. 588.

${ }^{8}$ ACCIOLY apud MAZZUOLI, Valerio de Oliveira. Principes généraux de la responsabilité internationale d' après la doctrine et la jurisprudence, in Recueil des Cours. Vol. 96, 1959-I, pp. 349-441. 
seus membros, teria legitimidade ativa para vindicar os seus direitos por via de reclamação internacional ${ }^{9}$.

Valério de Oliveira Mazzuoli conclui que esse fato demonstra que o conceito de responsabilidade internacional também é extensível às organizações internacionais intergovernamentais, que podem reclamar direitos, mas também serem demandadas por eventual violação de normas internacionais que acarretem prejuízos a terceiros ${ }^{10}$.

O Estudo da responsabilidade internacional do Estado e das organizações internacionais é hoje um dos mais importantes dentre as disciplinas do moderno Direito Internacional Público, tanto assim que a CDI o colocou em sua primeira sessão de 1949 no rol dos quatorze problemas prioritários do direito das gentes ${ }^{11}$.

As características da responsabilidade internacional estão atreladas a uma ideia de justiça, estando os Estados vinculados ao que assumiram no cenário internacional, devendo observar a boa-fé e o não prejuízo aos sujeitos do direito das gentes. Portanto, o Estado é internacionalmente responsável por toda ação ou omissão que lhe seja imputável de acordo com as regras do Direito Internacional Público, e das quais resulte violação abstrata de uma norma jurídica internacional por ele anteriormente aceita ${ }^{12}$.

Ian Brownlie assevera que:

O instituto da responsabilidade internacional do Estado, diferentemente da responsabilidade atinente ao Direito interno, visa sempre a reparação a um prejuízo causado a determinado Estado em virtude de ato ilícito praticado por outro. A reparação (civil) é a restitutio naturalis ou restitutio in integrum, tendo por finalidade restituir as coisas, tanto quanto possível, ao estado de fato anteriormente constituído,

\footnotetext{
${ }^{9}$ RESEK apud MAZZUOLI, Valerio de Oliveira. Direito internacional público..., cit., pp. 261-262.

${ }^{10}$ MAZZUOLI, Valerio de Oliveira. Curso de direito internacional público. 7. ed. Rev. dos Tribunais, 2013.

${ }^{11}$ Idem.

${ }^{12}$ Idem.
} 
fazendo voltar as coisas ao status quo como forma de satisfação ${ }^{13}$.

Valério de Oliveira Mazzuoli ressalta que a responsabilidade penal, no Direito Internacional, só possui lugar excepcionalmente, como nos casos de genocídio, dos crimes de guerra e dos crimes contra a humanidade, o que já caracteriza a responsabilidade pessoal do indivíduo (notadamente perante o Tribunal Penal Internacional). Portanto, a responsabilidade internacional praticamente desconhece a responsabilidade penal, como a imposição de penas, castigos ou outras formas congêneres de repressão criminal ${ }^{14}$.

\section{PROTEÇÃO DIPLOMÁTICA}

A proteção diplomática é aquela em que se opera de Estado para Estado. Ocorre que o indivíduo vítima de violação ajuíza uma queixa, chamada de reclamação ao Estado de sua nacionalidade para que este a proteja internacionalmente. Quando o Estado oferece essa proteção ele endossa a reclamação da vítima e toma como sua a queixa alegada ${ }^{15}$.

São condições para a concessão do endosso, desde o momento da ocorrência da lesão até a decisão final, consoante Valério de Oliveira Mazzuoli:

a) ser a vítima (pessoa física ou jurídica) nacional do Estado reclamante ou pessoa sob sua proteção. A naturalização com a exclusiva finalidade de ser protegida diplomaticamente não autoriza a concessão do endosso ${ }^{16}$.

b) ter a vítima esgotado os recursos internos (administrativos ou judiciais) disponíveis para a

\footnotetext{
${ }^{13}$ BROWNLIE apud MAZZUOLI, Valerio de Oliveira. Curso de direito internacional público. 7. ed. Rev. dos Tribunais, 2013, p. 590.

${ }^{14}$ MAZZUOLI, Valerio de Oliveira. Curso de direito internacional público. 7. Ed. Rev. Dos Tribunais, 2013.

${ }^{15}$ MAZZUOLI, Valerio de Oliveira. Curso de direito internacional público. 7. ed. Rev. dos Tribunais, 2013.

${ }^{16}$ Idem.
} 
salvaguarda dos seus direitos violados (desde que, é claro, essas vias internas existam e que haja a possibilidade concreta de serem elas previamente esgotadas, e desde que também não haja evidente denegação de justiça ${ }^{17}$.

O autor Valério de Oliveira Mazzuoli recorre às lições de Marco Gerardo MONROY Cabra, que discorre que ainda é condição para a concessão do endosso, ter a vítima agido corretamente e sem culpa, ou seja, não ter ela contribuído, com seu próprio comportamento, à criação do dano (instituição conhecida como teoria das mãos limpas) ${ }^{18}$.

Por outro lado, quando se tem em jogo um ato ilícito cometido por particular, será o seu Estado respectivo (e não o próprio particular) que sofrerá a responsabilização internacional (a menos que este ato não configure a violação de um tipo penal internacional, caso em que esta responsabilidade será pessoal) ${ }^{19}$.

"Destaque - se que a proteção diplomática deve ser requerida ao Estado de origem (de nacionalidade) do indivíduo e não ao seu Estado de residência ${ }^{20 "}$.

Consoante Valério de Oliveira Mazzuoli, foi o que decidiu a Corte Internacional de Justiça no parecer consultivo de 11 de abril de 1949, Réparations des dommages au servisse des Nations Unies, inICJ Reports:

A teoria da responsabilidade internacional tem sido também aplicada às organizações internacionais. Estas podem, inclusive, utilizar - se dá proteção diplomática em relação aos seus funcionários, de que foi exemplo o caso Bernadotte. A proteção diplomática, em certos casos, também pode ser exercida pelas agências ou organismos

\footnotetext{
${ }^{17}$ MAZZUOLI, Valerio de Oliveira. Curso de direito internacional público. 7. ed. Rev. dos Tribunais, 2013.

${ }^{18} \mathrm{Cf}$. CABRA, Marco Gerardo Monroy. Derecho internacional público. Cit., p. 547. apud MAZZUOLI, 2013.

${ }^{19}$ MAZZUOLI, Valerio de Oliveira. Curso de direito internacional público. 7. ed. Rev. dos Tribunais, 2013.

${ }^{20}$ Idem, p. 593.
} 
internacionais especializados da ONU. Esses casos são variantes modernas da chamada proteção diplomática - que, repita-se, não se confunde com os privilégios e imunidades diplomáticas, aos quais a doutrina atribui o nome de proteção funcional. Assim, tem-se a proteção diplomática para os casos relativos ao endosso do Estado na salvaguarda dos direitos dos seus nacionais, e a proteção funcional para aqueles atinentes à proteção que as organizações internacionais dão àqueles funcionários que se encontram a seu serviço. A proteção funcional baseia-se na ideia de que os agentes que servem a determinada organização internacional não devem precisar de outra proteção que não aquela da organização para a qual trabalha. Tais agentes não devem depender da proteção do seu Estado patrial nestes casos, sendo essencial que a sua proteção advenha da própria organização a que está servindo naquele momento ${ }^{21}$.

José Francisco Rezek, citado por Valério Mazzuoli, entende que um dos casos mais marcantes que deflagrou a moderna teoria da responsabilidade internacional do Estado ocorreu quando o mediador da ONU na Palestina, o conde sueco Folke Bernadotte, foi assassinado em Jerusalém em 17 de setembro 1948. Com ele morreu o coronel André Sérot, que liderava os observadores franceses. Ademais, outros agentes internacionais sofreram danos pessoais, em relação aos quais reclamaram indenização. A ONU então, por meio de Resolução de 3 de dezembro de 1948, solicitou um parecer consultivo à CIJ, a qual, em 11 de abril de 1949, manifestou -se no sentido de poder a organização internacional apresentar ao governo de jure ou de facto responsável pelo ilícito, que não se confunde com o mal diretamente sofrido pelas vítimas e seus sucessores, uma reclamação, a fim de poder reparar-se do dano sofrido. A Corte entendeu que a ONU, detentora de personalidade jurídica distinta da dos seus membros e como sujeito de direito das gentes que é, teria legitimidade ativa para vindicar os seus direitos por via de reclamação internacional ${ }^{22}$.

\footnotetext{
${ }^{21}$ MAZZUOLI, Valerio de Oliveira. Curso de direito internacional público. 7. ed. Rev. dos Tribunais, 2013. p. 594.
}

${ }^{22} \mathrm{Cf}$. RESEK. José Francisco. Direito internacional público. Cit., pp 261-262. 


\title{
3 FORMAS DE RESPONSABILIDADE INTERNACIONAL
}

\author{
Consoante Valério de Oliveira Mazzuoli:
}

São várias as formas conhecidas de responsabilidade internacional dos Estados, sendo as mais comuns as seguintes espécies: a) responsabilidade direta (principal) e indireta (subsidiária); b) responsabilidade por comissão e por omissão; e c) responsabilidade convencional e delituosa ${ }^{23}$.

A responsabilidade direta (ou principal) ocorre quando o ato ilícito (positivo ou negativo) for praticado pelo próprio governo estatal, por órgão governamental, por funcionário de seu governo ou por uma coletividade pública do Estado que age em nome dele. Também se enquadram nesta categoria os atos praticados por particulares, quando a prática do ato decorre da atitude do Estado em relação a este particular, ou seja, quando a atividade do particular possa ser imputada ao Estado. $\mathrm{O}$ artigo $8^{\circ}$ do draft da ONU prevê esta possibilidade, ao dizer que

[...] considerar-se-á ato estatal de acordo com o Direito Internacional a conduta de uma pessoa ou grupo de pessoas se a pessoa ou grupo de pessoas estiver de fato agindo por instruções ou sob a direção ou controle daquele Estado ao executar a conduta.

Por exemplo, no caso de tráfico de escravos ${ }^{24}$.

Hildelbrando Accioly, citado por Valério Mazzuoli, entende que:

Será indireta (ou subsidiária) a responsabilidade quando o ilícito for cometido por simples particulares ou por um grupo ou coletividade que o

${ }^{23}$ Réparations des dommages au servisse des Nations Unies, inICJ Reports, 1949, pp.183-184 apud MAZZUOLI, Valerio de Oliveira. Curso de direito internacional público. 7. ed. Rev. dos Tribunais, 2013. p. 597

24 ACCIOLY apud MAZZUOLI, Valerio de Oliveira. Curso de direito internacional público. 7. ed. Rev. dos Tribunais, 2013. p. 597. 
Estado representa na esfera internacional, a exemplo dos ilícitos cometidos por uma comunidade sob tutela estatal (um território sob mandato etc.) ou ainda por um Estado que o protege. Em verdade, os atos tipicamente particulares (praticados por indivíduos que não representam formalmente $o$ Estado) não podem dar causa a responsabilidade internacional do Estado, quando muito ocasioná$1 a^{25}$.

Já a responsabilidade será por comissão quando o ilícito internacional for decorrente de uma ação positiva do Estado ou de seus agentes, e por omissão quando o Estado (ou seus agentes) se omitir ou deixar de praticar um ato requerido pelo DIP, em relação ao qual ele tinha o dever jurídico de praticar $^{26}$.

\section{NATUREZA JURÍDICA DA RESPONSABILIDADE INTERNACIONAL}

Há duas grandes teorias acerca da natureza jurídica da responsabilidade internacional do Estado: a corrente subjetivista (teoria da culpa) e a objetivista (teoria do risco) ${ }^{27}$.

A teoria subjetivista, defendida por Hugo Grotius, sustenta que a responsabilidade internacional deve derivar de ato culposo (stricto sensu) do Estado ou doloso, em termos de vontade de praticar o ato ou evento danoso. Trata-se do velho princípio do Direito Romano qui in culpa non est, natura ad nihil tenetur. Ou seja, não basta a prática de um ato internacional objetivamente ilícito também é necessário que o Estado que o praticou tenha agido com culpa (imprudência, negligência ou imperícia) ou dolo intencional ${ }^{28}$.

25 ACCIOLY apud MAZZUOLI, Valerio de Oliveira. Tratado de direito internacional público. Vol. I, cit., p. 275.

${ }^{26}$ MAZZUOLI, Valerio de Oliveira. Curso de direito internacional público. 7. ed. Rev. dos Tribunais, 2013.

${ }^{27}$ MAZZUOLI, Valerio de Oliveira. Curso de direito internacional público. 7. ed. Rev. dos Tribunais, 2013.

${ }^{28}$ Idem. 
A doutrina objetivista, ou teoria do risco, por sua vez, pretende demonstrar a existência da responsabilidade do Estado no simples fato de ter ele violado uma norma internacional que deveria respeitar, não se preocupando em saber quais foram os motivos ou os fatos que o levaram a atuar delituosamente. Esta teoria foi afirmada por Triepel, seguido por Anzilotti, que rejeitava em definitivo a teoria da culpa. Para a teoria objetivista, portanto, a responsabilidade do Estado surge em decorrência do nexo de causalidade existente entre o ato ilícito praticado pelo Estado e o prejuízo sofrido por outro, sem necessidade de se recorrer ao elemento psicológico para auferir a responsabilidade daquele. Aqui está em jogo apenas o "risco" que, contudo, também integra o dolo, mas sem a existência de vontade específica, que o Estado assume ao praticar determinado ato (violador do Direito Internacional) ${ }^{29}$.

Esta teoria tem sido utilizada em casos que tratam da exploração cósmica e de energia nuclear, bem como os relativos à proteção internacional do meio ambiente e dos direitos humanos. ${ }^{30}$

Hans Kelsen em seu livro General theory of law and state enfatiza seu posicionamento:

[...] Mas o Estado não poder esquivar-se da responsabilidade provando apenas que seus órgãos não intencionalmente e não maliciosamente violaram uma norma de direito internacional. Se a responsabilidade é baseada na culpa (culpabilidade) é entendido não apenas os casos em que a violação foi cometida negligentemente, a responsabilidade internacional do Estado tem, com respeito aos indivíduos responsáveis coletivamente, a característica de responsabilidade objetiva; mas com respeito aos indivíduos nas quais suas condutas constituam em crime internacional, em princípio, o caráter da culpabilidade. Se, entretanto, a negligência não é concebida como um tipo de culpa - (culpa $)$ - e assinalamos, a opinião correta - a responsabilidade internacional do estado tem como

${ }^{29}$ MAZZUOLI, Valerio de Oliveira. Curso de direito internacional público. 7. ed. Rev. dos Tribunais, 2013.

${ }^{30}$ Idem. 
característica a responsabilidade objetiva, em todo respeito. ${ }^{31}$

Jules Basdevant, citado por Valério de Oliveira Mazzuoli, discorre que ressalta que:

Em relação à proteção dos direitos humanos, tem-se entendido que os Estados têm obrigação de controlar os seus órgãos e agentes internos a fim de evitar violações sucessivas às obrigações contraídas em sede convencional, sob pena de responsabilidade internacional, o que contribui para dar mais efetividade (effet utile) aos tratados de proteção dos direitos humanos e aos seus propósitos ${ }^{32}$.

Valério de Oliveira Mazzuoli salienta que a jurisprudência internacional, entretanto, ainda continua se utilizando em larga escala da teoria subjetivista (ou teoria da culpa), visto que esta protege mais o Estado do que a teoria objetivista ou do risco. Esta última tem sido ainda aplicada em pequena escala na jurisprudência internacional, mesmo que já se tenha começado a perceber um certo aumento de decisões a seu favor $(2013)^{33}$.

\section{ORGÃOS INTERNOS E RESPONSABILIDADE INTERNACIONAL}

Valério de Oliveira Mazzuoli registra que:

O Institut de Droit International, na sua sessão de Lausanne de 1927, da qual foi relator o Sr. Leo Strissower, apesar de não ter tomado partido na

\footnotetext{
${ }^{31}$ KELSEN, Hans.General theory of law and state. v.l. The Lawbook Exchange Ltd., 1945. p. 360.11.

${ }^{32}$ BASDEVANT apud MAZZUOLI, Valerio de Oliveira.Règles génerales du droit de la paix, in Recueil des Cours. Vol. 58. 1936, IV. pp. 670-674.

${ }^{33}$ MAZZUOLI, Valerio de Oliveira. Curso de direito internacional público. 7. ed. Rev. dos Tribunais, 2013.
} 
controvérsia relativa à questão de culpa, manisfestou-se expressamente no sentido de que o Estado "é responsável pelos danos causados aos estrangeiros por todas as ações ou omissões contrárias às suas obrigações internacionais, qualquer que seja a autoridade do Estado de onde elas provêm: constituinte, legislativa, governamental ou judiciária ${ }^{34}$.

Veremos então cada um desses casos separadamente, discutindo-se também, ao final, os atos praticados por indivíduos na sua condição de particular, não em nome do Estado ${ }^{35}$.

Thomas Buergenthal, citado por Valério de Oliveira Mazzuoli ressalta que:

a) Atos do executivo. O Poder Executivo ainda é o grande vilão e maior responsável pelo cometimento de ilícitos e pela violação de normas internacionais, quer por meio da atividade governamental, quer pela ação funcional de seus servidores. Todos os atos ilícitos internacionais praticados pelo Executivo diretamente ou pelos seus funcionários e agentes, tanto no âmbito interno como no âmbito internacional, são geradores de responsabilidade. São exemplos de tais práticas, levadas a efeito diretamente pelo Executivo, a conclusão de contratos ou concessões, prisões ilegais ou arbitrárias, a concessão de anistia contrária às regras do Direito Internacional, $[\ldots]^{36}$.

Segundo Valério de Oliveira Mazzuoli, entende-se que perante a violação dos tratados, o descumprimento dos laudos arbitrais e decisões

\footnotetext{
${ }^{34}$ MAZZUOLI, Valerio de Oliveira. Curso de direito internacional público. 7. ed. Rev. dos Tribunais, 2013. p. 599.

${ }^{35}$ Ibidem.

36 BUERGENTHAL apud MAZZUOLI, Valerio de Oliveira. Manual de derecho internacional público. cit., p. 118.
} 
judiciárias internacionais, a violação da fronteira de outro Estado em tempo de paz, as injustiças cometidas contra estrangeiros etc ${ }^{37}$.

Da mesma forma, o descumprimento de proteção às pessoas acreditadas por potências estrangeiras, como os chefes de Estados, representantes diplomáticos e chefes de delegações internacionais, também torna o Executivo responsável internacionalmente, uma vez que é seu dever proteger essas pessoas quando em seu território ${ }^{38}$.

Outro caso de que os tratadistas pouco se ocupam, lembrado por Accioly, diz respeito à inexecução de decisões judiciárias de última instância favoráveis a estrangeiros:

Aqui não se trata propriamente de denegatio justitia, por não se tratar de ato de órgão judiciário, não obstante várias decisões arbitrais e judiciárias a esta se equipararem. A inexecução, neste caso, "representa praticamente o mesmo que a ausência da devida proteção judiciária e, portanto, deve acarretar a responsabilidade internacional do Estado ${ }^{39}$.

Valério de Oliveira Mazzuoli assevera que:

Os atos diretamente praticados pelo governo não excluem a prática de atos ilícitos cometidos por agentes ou funcionários do Executivo, tanto em território nacional quanto em território estrangeiro. O Estado responde pelo ilícito internacional mesmo no caso de o funcionário ser incompetente para a prática do ato, pois a qualidade oficial do funcionário (que agiu na qualidade de órgão estatal) vincula sempre o Estado (que não deixa de estar ligado ao seu agente), salvo se sua incompetência era tão flagrante que deveria tê-la percebido $o$ estrangeiro lesado. No caso dos atos ilícitos praticados pelo Estado por meio de seus agentes

${ }^{37}$ MAZZUOLI, Valerio de Oliveira. Curso de direito internacional público. 7. ed. Rev. dos Tribunais, 2013.

${ }^{38}$ BUERGENTHAL Manual de derecho internacional público, cit., p. 118.

39 ACCIOLI apud MAZZUOLI, Valerio de Oliveira. Tratado de direito internacional público. Vol. I, cit., pp. 285-286. 
(mesmo que incompetentes), o que se leva em consideração para a aferição do quantum de sua responsabilidade é o fato de ter o funcionário agido nos limites aparentes de suas funções, uma vez que não se exige de qualquer potência estrangeira (ou um particular estrangeiro) que conheça os limites estreitos da atuação funcional do agente do Estado que lhe prejudicou. A aparência dos atos de tais funcionários - que são geralmente agentes diplomáticos, cônsules ou oficiais militares - é suficiente para atribuir ao Estado lesado os direitos de imputar ao outro sua responsabilidade internacional (que, neste caso, será objetiva)" ${ }^{40}$.

Valério de Oliveira Mazzuoli (2013) reporta-se a lições de Hildebrando Accioly, em seu Tratado de direito internacional público, que assevera que existe um caso que é um bom exemplo desse tipo de responsabilidade por atos do executivo que é a Reclamação Massey. Massey foi assassinado por autoridades mexicanas. Ocorre que se tratava de um cidadão norte-americano (Sr. Massey). A reclamação foi apresentada em nome da viúva deste a título pessoal e como tutora dos dois fillhos menores do casal e fez com que os Estados Unidos recebessem 15.000 dólares em 1927. O México não tomou as medidas necessárias então foi aplicado o princípio de que sempre que uma conduta ilícita por parte de pessoas (a serviço do Estado), seja qual for o seu estatuto particular ou categoria ao abrigo do Direito interno, resultar no não cumprimento por parte de uma nação das suas obrigações em virtude do Direito internacional, essa nação deve arcar com a responsabilidade pelos atos ilícitos dos seus funcioná$\operatorname{rios}^{41}$.

Atos do Legislativo - de acordo com o que decidiu a antiga CPJI, (Corte Permanente de Justiça) em 1932: o Poder Legislativo viola o Direito Internacional em quatro hipóteses distintas. A primeira ocorre quando o Parlamento edita leis contrárias ao conteúdo de tratados inter-

${ }^{40}$ MAZZUOLI, Valerio de Oliveira. Curso de direito internacional público. 7. Ed. Rev. dos Tribunais, 2013. p. 601.

${ }^{41} \mathrm{Cf}$. ACCIOLY, Hildebrando. Tratado de direito internacional público. Vol. I. Cit., pp. 285-286 
nacionais anteriormente aprovados por ele mesmo e já em vigor internacional, burlando aquilo que o Estado pactuou internacionalmente ${ }^{42}$.

Para Valério de Oliveira Mazzuoli, remetendo-se a Marcílio Toscano Franca Filho, este entende que:

A segunda tem lugar quando o legislativo revoga certa lei necessária à correta aplicação de um tratado, deixando o instrumento inoperável por ausência de base legislativa. Em sentido inverso, na terceira hipótese, o Legislativo incorre em responsabilidade internacional se deixa de aprovar determinada legislação necessária ao cumprimento do tratado ratificado e em vigor. Por fim, em quarto lugar a responsabilidade internacional do Estado aparece quando o Legislativo deixa de revogar legislação contrária ao conteúdo de um tratado em vigor no Estado $^{43}$.

Quanto ao tema da responsabilidade internacional do Estado pela criação e aplicação de leis contrárias ao conteúdo de tratados, a Corte Interamericana de Direitos Humanos na Opinião Consultiva $n^{\circ} 14$, de 9 de dezembro de 1994 respondeu à questão apresentada pela Comissão Interamericana de Direitos Humanos sobre quais seriam os efeitos jurídi$\cos$ da lei que manifestamente viola obrigações que o Estado-parte, na convenção Americana sobre Direitos Humanos, contraiu ao ratificar a Convenção. A Corte-Interamericana foi clara e não deixou dúvidas: à luz das regras do Direito Internacional, não se pode invocar disposições do Direito interno estatal como justificativa para o descumprimento de obrigações internacionais (parágrafo 35), concluindo que a promulgação de uma lei manifestamente contrária às obrigações assumidas por um Estado ao ratificar ou aderir à Convenção, constitui uma violação desta capaz de

\footnotetext{
${ }^{42}$ MAZZUOLI, Valerio de Oliveira. Curso de direito internacional público. 7. Ed. Rev. dos Tribunais, 2013.

43 FRANCA FILHO apud MAZZUOLI, Valerio de Oliveira. O silêncio eloquente: omissão do Estado na Comunidade Europeia e no Mercosul. Coimbra: Almedina, 2008, p. 242.
} 
gerar, quando afete direitos e liberdades protegidos de determinados indivíduos, a responsabilidade internacional para esse mesmo Estado ${ }^{44}$.

A responsabilidade internacional do Estado passa a existir a partir do momento em que a lei entra em vigor, e não quando foi aprovada. A vacatio legis só entra em vigor quando expirado o prazo da vacatio, considerando-se, então, a partir daí, o momento de sua aplicabilidade e o início do comprometimento do Estado para com as regras internacionais desrespeitadas por ato do Legislativo ${ }^{45}$.

Segundo leciona Valério de Oliveira Mazzuoli:

c) Atos do Judiciário. Os atos do poder judiciário são atos estatais e como tais devem ser compreendidos em matéria de responsabilidade internacional, pois a atuação jurisdicional também pratica ilícito internacional. Isso ocorre quando a justiça de um país julga em desacordo com tratado internacional ratificado pelo Estado e em vigor internacional, ou mesmo quando não julga com base em tratado internacional que deveria conhecer, denegando o direito da parte que o invoca com base em convenções internacionais.Trata-se, neste caso, da hipótese em que o Estado, por meio do seu Poder Judiciário, recusa deliberadamente a aplicação da justiça, impossibilitando, por exemplo, um estrangeiro de obter o provimento que solicita (caso em que passa a caber a este o instrumento da reclamação diplomática), ou mesmo quando a decisão judicial é contrária às obrigações internacionais assumidas pelo Estado no âmbito internacional ${ }^{46}$.

Não podemos olvidar que o não cumprimento de sentença proferida por tribunal com jurisdição internacional pelo judiciário estatal também é causa de responsabilidade internacional do Estado. O Estado que aceita a competência contenciosa de um tribunal internacional está

\footnotetext{
${ }^{44}$ MAZZUOLI, Valerio de Oliveira. Curso de direito internacional público. 7. Ed. Rev. dos Tribunais, 2013.

${ }^{45}$ Idem.

${ }^{46}$ Idem.
} 
obrigado a dar cumprimento à decisão que, porventura, vier a ser proferida. Caso o Estado não o faça, este estará descumprindo obrigação de caráter internacional e ficará sujeito a sanções que a sociedade internacional houver por bem lhe aplicar ${ }^{47}$.

Atos dos indivíduos - Não são estranhos ao Direito Internacional determinados atos praticados por indivíduos na sua condição de particular. Esses atos lhes são diretamente imputáveis, tais como a pirataria, o tráfico de entorpecentes e drogas afins, o tráfico de escravos e ainda o transporte de produtos contrabandeados e a violação do bloqueio. Tais atos não acarretam necessariamente a responsabilidade internacional do Estado. Existem, contudo, certos atos praticados por particulares, capazes de onerar o Estado respectivo de responsabilidade internacional. Neste caso, a responsabilidade estatal não decorre propriamente do ato de um indivíduo, que vínculo nenhum mantinha com o Estado e que não atuou em nome deste, mas de uma conduta negativa do Estado relativamente às obrigações que lhe impõem o Direito Internacional ${ }^{48}$.

Mazzuoli:

$\mathrm{Na}$ perspectiva de Hildebrando Accioly citado por Valério

São vários os atos de particulares que podem dar causa, para o Estado em questão, à sua responsabilidade internacional. Os mais comuns deles são os atentados praticados por indivíduos contra chefes de Estado estrangeiro ou contra os seus representantes diplomáticos, os insultos à bandeira ou aos símbolos nacionais de determinado Estado, as publicações injuriosas contra a dignidade do outro Estado, os atos de apoio armado a uma insurreição etc. Outro caso comum de ocorrer é o dano ou a violência a estrangeiros cometidos por particulares no território do Estado. Mas, por que um Estado deve ser responsabilizado por atos de indivíduos que não atuaram em seu nome, quando da prática do ilícito internacional? Neste caso, a responsabilidade existe pela culpa do Estado (sem a qual não há que se falar em responsabilidade) que, podendo evitar o

${ }^{47}$ MAZZUOLI, Valerio de Oliveira. Curso de direito internacional público. 7. Ed. Rev. dos Tribunais, 2013.

${ }^{48}$ Idem. 
ato lesivo não o evitou, ou ainda, que tendo tomado conhecimento do fato subtraiu o delinquente à punição. Em suma, não é o ato do indivíduo em si que acarreta a responsabilidade internacional do Estado, mas a conduta deste próprio que não observou o que o Direito Internacional Público lhe impõe em relação a pessoas ou bens em seu território ${ }^{49}$.

Conforme Clóvis Bevilacqua, remetido por Valério Mazzuoli, as lesões aos direitos de estrangeiros praticadas por particulares não acarretam a responsabilidade internacional do Estado. Neste caso, a solução seria a de responsabilizar o autor do ato nas esferas civil e criminal. Ocorre que se não se puder, com um mínimo de razoabilidade, atribuir ao Estado respectivo a negligência ou cumplicidade na prática do ato manifestado pelo seu súdito, o mesmo ficará desonerado de responder internacionalmente pelo ato do particular ${ }^{50}$.

\section{PRÉVIO ESGOTAMENTO DOS RECURSOS INTERNOS}

Os Estados, às vezes, indenizam quase que imediatamente indivíduos que tiveram seus direitos violados por atos de agentes seus. Como exemplo do cidadão francês agredido por atos de autoridades brasileiras no Rio Grande do Sul. No caso, o Brasil acabou indenizando a vítima por questão de equidade, independentemente de ela ter esgotado os meios possíveis de se satisfazer, neste país, dos prejuízos sofridos ${ }^{51}$.

Como regra para que um Estado possa exercer a proteção diplomática em favor dos seus nacionais (protegendo direitos destes, vítimas de violações do Direito Internacional) é necessário que, antes disso, o sujeito lesado esgote todos os recursos jurídicos internos dos tribunais do Estado que cometeu o ilícito ou do Estado onde este ilícito foi cometido. Trata-se da regra universalmente aceita do prévio esgotamento dos recur-

\footnotetext{
${ }^{49}$ ACCIOLY, Valerio de Oliveira.

${ }^{50}$ Cf. BEVILAQUA, Clóvis. Direito público internacional..., t. I, cit., pp. 227 228.

${ }^{51}$ MAZZUOLI, Valerio de Oliveira. Curso de direito internacional público. 7. Ed. Rev. dos Tribunais, 2013.
} 
sos internos (no francês, épuisement préalable des recours internes). Portanto, a responsabilidade internacional do Estado não se achará comprometida antes de esgotados todos os meios possíveis, previstos no Direito Interno ${ }^{52}$.

O fundamento em ser assim a regra encontra suporte na subsidiariedade do sistema protetivo internacional relativamente ao sistema judiciário interno. Esse fundamento encontra-se na interpretação no Direito Internacional dos Direitos Humanos, uma vez que não se pode aguardar eternamente o pronunciamento da mais alta corte de um país, principalmente naqueles Estados em que a boa vontade na resolução dos litígios parece ser resquício histórico ${ }^{53}$.

Entende-se ser justa a exigência do prévio esgotamento dos recursos porque se dá oportunidade ao Estado de reparar a questão dentro do seu ordenamento jurídico; impede-se que seja deflagrada uma demanda internacional sem motivo justificável e se evitam os pedidos abusivos de proteção diplomática ${ }^{54}$.

Em suma, o esgotamento de todos esses recursos significa, no Brasil, chegar ao Supremo Tribunal Federal, que é a última instância judiciária da Justiça brasileira (salvo se a última instância da causa for o Superior Tribunal de Justiça, nos casos em que não estiver presente a competência do STF). E mesmo que o recurso à última instância tenha sido eficaz (provido) para o reclamante, pode este último bater às portas do judiciário internacional demonstrando interesse, a fim de demonstrar seus direitos eventualmente não concedidos integralmente no plano inter$\mathrm{no}^{55}$.

Consoante Valério Mazzuoli, dada a asserção das normas de proteção dos direitos humanos em nível mundial, esta regra pode ser flexibilizada ou mitigada em determinados casos, como na denegação de justiça ou quando os recursos internos se mostrem flagrantemente falhos, inoperantes, ou inacessíveis ao sujeito lesado, quando então fica permitido, desde esse momento, o ingresso com a reclamação pela via diplomática $(2013)^{56}$.

${ }^{52}$ MAZZUOLI, Valerio de Oliveira. Curso de direito internacional público. 7. Ed. Rev. dos Tribunais, 2013.

${ }^{53}$ Idem.
${ }^{54}$ Idem.
${ }^{55}$ Idem.
${ }^{56}$ Idem. 


\section{APRESENTAÇÃO DE RECLAMAÇÕES}

Nos casos acima citados e também naqueles em que o indivíduo não obtenha a satisfação de seus direitos (tendo então esgotado os recursos internos dos tribunais desse estado, sem que seu direito fosse reconhecido), seu Estado patrial pode, discricionariamente, tornar sua a reclamação de seu nacional, trazendo para si as "suas dores", passando então a atuar como Estado em nome daqueles que tiveram seus direitos violados pela outra potência soberana ${ }^{57}$.

Sob a perspectiva de Thomas Buergenthal:

Caso entenda o Estado patrial que o seu nacional realmente foi ofendido em seus direitos, a questão se torna assunto internacional do qual serão partes este Estado e aquele outro Estado o qual se faz a reclamação. Em muitos casos, uma solução amigável resolve o problema. Mas caso esta não surta efeitos, os Estados-partes no litígio podem optar pelo estabelecimento de um tribunal arbitral internacional ou, em último caso, bater às portas da CIJ. Mas frisese que, em caso de condenação pecuniária, tudo que é recebido pelo Estado reclamante passa a ser propriedade exclusiva deste, ainda que o seu Direito interno exija um repasse desse montante para a pessoa física ofendida que ele representou internacionalmente. Com isto, entretanto, o Direito Internacional não se preocupa ${ }^{58}$.

Valério de Oliveira Mazzuoli recorre à doutrina de Garcia Amador que entende que o direito de proteção diplomática pertence ao Estado e não ao reclamante. Dessa maneira, mesmo que o estrangeiro pretenda ir a um país para fazer negócios e renuncie à proteção diplomática, (doutrina Calvo) são os Estados nacionais de tais estrangeiros que

${ }^{57}$ MAZZUOLI, Valerio de Oliveira. Curso de direito internacional público. 7. Ed. Rev. dos Tribunais, 2013. p. 609.

${ }^{58}$ BUERGENTHAL Manual de derecho internacional público, cit., pp. 119120 apud MAZZUOLI, Valerio de Oliveira. Curso de direito internacional público. 7. ed. Rev. dos Tribunais, 2013. 
detêm a proteção diplomática e não o reclamante. Por consequência, essas cláusulas não os privam em absoluto da proteção diplomática ${ }^{59}$.

Para Ian Brownlie, em seu livro Princípios do direito internacional público, este assevera que para que um Estado apresente uma reclamação internacional contra outro são necessários alguns requisitos, que não se confundem com as condições para a concessão do endosso. A presença do correto endereçamento é fundamental, sob pena de o outro Estado alegar, em exceções preliminares, a incompetência do tribunal, caso a reclamação, é obvio, tenha sido proposta perante um tribunal internacional. O prazo é outro requisito (ratione temporis) ensejador de exceção impeditiva da análise do mérito e somente em casos excepcionais os tribunais podem aceitar reclamações extemporâneas. Somente poderá aceitar quando o Estado peticionário prova que a perda do prazo se deu em virtude de ameaça ou uso da força por parte do Estado reclamado. $\mathrm{O}$ interesse jurídico do autor da demanda, que é coisa distinta do litígio propriamente dito, não fica também alheio à análise do tribunal ${ }^{60}$.

\section{EXCLUDENTES DA RESPONSABILIDADE}

Valério de Oliveira Mazzuoli remete às lições de Eduardo Correia Baptista, pois observa este que não são todos os ilícitos internacionais que acarretam a responsabilidade internacional do Estado. Existem determinadas circunstâncias capazes de excluí-la, estas são causa de justificação e permitem a um Estado, ou outro sujeito, vinculado a uma norma internacional, praticar licitamente um ato que em condições normais seria tido por ilícito. Destaque-se que segundo o draft, uma norma de jus cogens, Direito Internacional Geral, não comporta exceções de excludentes de ilicitude. Portanto, um Estado que viola o jus cogens internacional não

${ }^{59} \mathrm{Cf}$. AMADOR, Garcia. Recent Codification of the law of State responsibility for injuries to aliens. Dobbs Ferry, N.Y.: Oceana Publications, 1974, pp. 291-294 apud MAZZUOLI, Valerio de Oliveira.

${ }^{60} \mathrm{Cf}$. BROWNLIE, Ian. Princípios de direito internacional público. Cit., p. 474; Apud MAZZUOLI Valerio de Oliveira. Curso de direito internacional público. 7. ed. Rev. dos Tribunais, 2013. 
terá meios de se livrar da responsabilidade internacional decorrente de sua violação ${ }^{61}$.

Entre os meios de exclusão de ilicitude, sob a perspectiva de Valério de Oliveira Mazzuoli encontram-se:

a) Consentimento do Estado. $\mathrm{O}$ consentimento válido dado por um Estado à realização de determinado ato por outro Estado exclui a ilicitude daquele ato em relação a este último. Trata-se da regra volenti non fit injuria ("não há injúria quando há consentimento") à teoria da responsabilidade internacional $[\ldots]^{62}$.

a) Legítima defesa. Exclui-se a ilicitude de um ato se o mesmo resulta em legítima defesa. Este pressupõe sempre uma agressão armada injusta e uma reação estatal imediata. Esta ocorre em razão da necessidade de defesa, necessária à preservação de pessoas e da dignidade do Estado. Também ocorre por meio de uma medida lícita de defesa, sendo necessária e proporcional ao ataque ou perigo eminente ${ }^{63}$.

b) Contramedidas. Outrora chamadas de represálias, as contramedidas são, em verdade, atos ilícitos. Justificam-se, porque seriam a única forma de revidar outros atos ilícitos cometidos pelo Estado agressor. Para a CDI da ONU, as contramedidas têm como finalidade resolver o problema em causa. Estas são admitidas somente quando tiverem por fundamento um ataque prévio do outro Estado, contrário ao direito do ofendido e forem proporcionais ao ataque ${ }^{64} . \mathrm{Em}$ suma, consoante Crawford entende-se que "trata-se da possibilidade que o Estado possui de recorrer à justiça privada ${ }^{65}$ ".

${ }^{61}$ Cf. Baptista, Eduardo Correia. O poder público bélico em direito internacional: o uso da força pelas Nações Unidas em especial. Coimbra: Almedina, 2003, p. 103.

${ }^{62}$ MAZZUOLI, Valerio de Oliveira. Curso de direito internacional público. 7. ed. Rev. dos Tribunais, 2013, p. 610.

${ }^{63}$ Idem.

${ }^{64}$ Idem.

${ }^{65}$ Idem. 
c) Força maior. $\mathrm{O}$ ato ilícito quando ocorra por meio de um evento externo irresistível ou imprevisto, será acobertado pela excludente de responsabilidade ${ }^{66}$.

d) Perigo extremo. Esta excludente encontra-se no draft das Nações Unidas no artigo $24 \S 1^{\circ}$. De acordo com Valério de Oliveira Mazzuoli,

[...] no qual ficará excluída a ilicitude de um ato estatal em desacordo com uma obrigação internacional se o autor do ato em questão não dispõe de nenhum outro modo razoável, em uma situação de perigo extremo, de salvar a vida do autor ou vidas de outras pessoas confiadas aos seus cuidados. ${ }^{67}$.

e) Estado de necessidade. O estado de necessidade é uma causa de exclusão de responsabilidade reconhecida pelo Direito Internacional costumeiro. Porém, este não desonera o Estado de sua responsabilidade internacional, uma vez que não é facultada a nenhuma potência estrangeira a proteção de seu território em detrimento dos direitos de terceiros. Quanto ao draft da convenção da ONU, este segue esta vertente doutrinária, em seu artigo ${ }^{68}$.

f) Renúncia do indivíduo lesado. Trata-se da chamada doutrina Calvo, Carlos Calvo, cujos ensinamentos são remetidos por Valério de Oliveira Mazzuoli, parte de um pressuposto que um particular pode renunciar à proteção pela via diplomática, por meio de um contrato prévio com um governo estrangeiro. Seria tal doutrina baseada numa cláusula inserta nos contratos celebrados pelo Estado com concessionários estrangeiros, estes últimos comprometem-se a não recorrer à proteção diplomática dos seus países de origem, caso surjam ali questões sobre a inexecução ou execução desses mesmos contratos. Essa cláusula Calvo tem aplicação na prática quanto a contratos de concessão, em que os nacionais estrangeiros renunciam à proteção diplomática de seu Estado patrial em

${ }^{66}$ CRAWFORD apud MAZZUOLI, Valerio de Oliveira. Brownlie's principles of public international law. Cit., p. 585.

${ }^{67}$ MAZZUOLI, Valerio de Oliveira. Curso de direito internacional público. 7. ed. Rev. dos Tribunais, 2013. p. 612.

${ }^{68}$ Idem. 
caso de litígio judicial envolvendo o objeto do contrato. Foi reconhecida que a proteção diplomática pode ser dispensada a estrangeiros e renunciada por estes, entretanto não passou imune a críticas, principalmente a de que a proteção diplomática não seria direito disponível do particular, mas de seu Estado de origem. Essa cláusula possui um êxito crescente em sua utilização. ${ }^{69}$

\section{CONSIDERAÇÕES FINAIS}

Ao analisar a problemática da concreta aplicação da responsabilidade internacional dos Estados na sociedade internacional, concluiu-se que é fundamental a criação de tribunais internacionais de variada natureza, para resolver questões das mais diversas apresentadas no contexto das relações internacionais. Entretanto, é necessário que o Estado membro conceda o aceite para a atuação das Cortes, havendo um limite de atuação desta para com os Estados em geral, podendo atuar somente perante os Estados membros da Convenção, possuindo, portanto, caráter subsidiário e complementar.

A teoria subjetivista tem sido utilizada em casos que tratam da exploração cósmica e de energia nuclear, bem como os relativos à proteção internacional do meio ambiente e dos direitos humanos. Kelsen e os Tribunais Internacionais têm defendido a imposição da teoria objetivista.

\section{REFERÊNCIAS BIBLIOGRÁFICAS}

KELSEN, Hans. General theory of law and state. The Lawbook Exchange Ltd., 1945. v.1.

MAZZUOLI, Valerio de Oliveira. Curso de direito internacional público. 7. ed. Rev. dos Tribunais, 2013.

RESEK, Francisco. Direito internacional público.13. ed. Cidade: Saraiva, 2012.

${ }^{69}$ MAZZUOLI, Valerio de Oliveira. Curso de direito internacional público. 7. ed. Rev. dos Tribunais, 2013. p. 612. 